\title{
The Development of Geomatics Education in Hong Kong
}

\author{
Lilian S.C. Pun-Cheng \\ Department of Land Surveying and Geo-Informatics, The Hong Kong \\ Polytechnic University
}

\section{Tammy Y.L. Kwan}

Department of Curriculum Studies, The University of Hong Kong, Pokfulan Road, Hong Kong

Exactly what is 'geomatics'? This is a question frequently raised by university applicants, their parents and the public. It is not surprising as the term is still missing from many world-renowned dictionaries. Nevertheless, the label 'geomatics' has been replacing the name of many traditional departments of surveying around the world, including North America, Europe and Asia, for almost ten years. The new name in fact has reflected a broadening of the curriculum from traditional land surveying to a variety of land data collection, manipulation and analysis techniques of related disciplines like remote sensing, photogrammetry, global positioning systems (GPS), geographic information systems (GIS) and digital mapping. It also embraces the idea of technological integration and application in environmental and human science related disciplines such as Earth science, biology, geography and social studies. Geomatics is a much broader concept than GIS. A GIS is a system of hardware, software and procedures designed to support the capture, management, manipulation, analysis, modelling and display of spatially-referenced data for solving complex planning and management problems (Goodchild \& Kemp, 1990). Hence GIS is a tool to provide access to various data sources and formats arising from maps, satellite imageries, aerial photographs and field measurements which can be used within the broader context of geomatics.

These changes in knowledge boundaries raise some questions. Should the high school curriculum also be expanded or modified from a traditional data collection and measurement approach in response to this changing technology? Is there sufficient support, in terms of facilities, expertise and financial input, to promote such curriculum expansion and integration? To answer these questions, an examination of the development of geomatics throughout the various education sectors in Hong Kong may illustrate the possibilities and problems.

In Hong Kong, land surveying at university level was uniquely offered by the Centre of Land Surveying and Engineering Surveying of The Hong Kong Polytechnic University (formerly The Hong Kong Polytechnic) from 1984 to 1991 in its three-year Higher Diploma (HD) course in land surveying and cartography. Only high school science students who had taken physics and mathematics were 
admitted to the course. With the grow th of the centre to the present department, newer and more advanced courses at undergraduate and post-graduate levels were introduced. Since 1991, the first intake of the Bachelor of Science (BSc) in land surveying and geo-informatics started to offer places to both science and arts students with preference given to subjects such as physics, mathematics, geography and/or computer studies. On the other hand, the three-year HD was restructured to a two-year course of HD in land surveying in 1992, and then to an $\mathrm{HD}$ in geomatics in 1998. Admission requirements are similar to that of the BSc course except that they allow for a lower academic attainment on entry.

The emergence of newer and more diverse courses reflects the changing employment market of the profession. In the 1980s, the three-year HD graduates were exempted from Part I and II examinations of the Royal Institute of Chartered Surveyors while BSc graduates today are exempted from the written examinations of the Hong Kong Institute of Surveyors. These qualifications pave the way to become a professional surveyor provided that graduates gain the necessary practical experience and pass the Assessment of Professional Competence test. On the other hand, the co-existence of an HD course aims at training survey and mapping technical officers especially in view of the high current level of demand for such specialisms as a result of Hong Kong's numerous large-scale construction projects. In recent years, as the GIS industry has been growing in both the commercial and governmental sectors, more graduates have been finding their careers moving in the broader direction of spatial data integration and analysis instead of in the narrower surveying profession, which deals primarily with field data collection. Hence geomatics graduates have the advantage of securing such jobs since they are well equipped with a thorough knowledge of spatial science, from the stage of various data collection methods to analysis and presentation. It is a course with a heavy technical and programming component.

Concerning university geography training, The University of Hong Kong, The Chinese University of Hong Kong and The Baptist University all have incorporated geomatics options such as 'Environmental GIS' and 'Geography of Information Technology' into their curriculum. These do not lead to professional recognition in surveying or geomatics but are designed to be less technically and more application-oriented, such as in the fields of urban planning, environmental management and transportation. This is also true for the Centre of Urban Planning and Environmental Management of The University of Hong Kong, in which the GIS curriculum is specially designed for urban planning applications. Hence, graduates who might normally find their careers in diverse sectors such as education, transport, business, agriculture and fishing, all find it advantageous to have expertise in the geomatics-related technology of GIS.

The promotion of geomatics education and professional development relies not only on the effort of tertiary educators and policy makers, but also on the provision of an adequate spatial data infrastructure. Topographic and thematic map production in Hong Kong is the responsibility of the Survey and Mapping Office (SMO) of the Lands Department. Traditionally, land information was collected by surveyors at a very large scale. As Hong Kong is a very densely populated place, undergoing rapid changes in land use, the work of surveyors is almost entirely concentrated on urban lowlands. Information for hilly areas is 
drawn from aerial photographs (photogrammetric plots) at a scale of about $1: 20,000$. Such information is then manipulated, classified, symbolised, drawn and reproduced manually to a scale of 1:1000 map sheets for public use. The 1:5000 series are just combinations of these large-scale map sheets photomechanically reduced with limited generalisation. On the other hand, the 1:20,000 (16 sheets), 1:50,000 ( 2 sheets) and 1:100,000 (1 sheet) maps are all separate productions in terms of information extraction, map design and revision. All these maps and aerial photographs of varying scales have long been used in high school and university geography teaching for land information measurement and interpretation.

With the advancement of computing technology and the awareness of the need for a complete database for different users, the Hong Kong government planned to convert all analogue land information into digital format. The Land Information Centre (LIC) was set up in the late 1980s as an affiliated body to the SMO. Analogue map conversion into digital format has been completed for the scales of 1:20,000,1:10,000,1:5000 and 1:1000 series. The major difference of these data sets from paper maps is that spatial features (e.g. buildings, roads) are now associated with more descriptions (e.g. names, address, type). These, when combined with other available socioeconomic information, would enable more meaningful and accurate analyses of geographical phenomena. In fact, apart from government departments themselves, the academic institutions, especially the above-mentioned surveying, geo-informatics and geography departments, have been frequent users of these digital land data for their research and teaching.

At university level, therefore, there has been considerable progress. What about the corresponding changes in schools? Despite the very sound and innovative benefits that GIS can bring to the IT age of learning, its actual practice and use in schools appears to have been received with much hesitation. Informal discussions were held with a number of Hong Kong geography teachers and, whilst they all expressed the view that GIS offered excellent potential for extended activities beyond conventional classroom teaching, they raised the practical constraints of actual classroom use because of the time needed for data entry. One geography teacher cited the example of his experience using GIS to study air pollution. A model was created but the project was only possible through direct collaboration with the software company and opportunities for students' hands-on learning were limited. Nevertheless, the resultant model can be used for teaching and the three-dimensional tools of the GIS package can be employed to give a more realistic visual impression of the various parameters or attributes studied. The software can also manipulate a mass of data in seconds. Aside from these perceived benefits, most of the teachers felt that the product of such manipulation was simply just another piece of data stored in the computer for ready retrieval. The obvious limitations and/or difficulties considered by the teachers are in three areas. First, there is the constant need to collect, update and create a local data bank to work on local issues. For this, they require collaboration with governmental departments and other institutional bodies. Second, even with the availability of data, limited class time does not allow in-depth discussion to make sense out of these data. Many teachers see the need to lengthen the teaching time from one lesson to at least three lessons (dealing with the teaching of the same 
topic) to handle data collection, data input and in-depth data discussion, analysis and interpretation, before effective learning impact can be felt. Third, teachers are required to have some programming background and knowledge to facilitate efficient data input and interpretation. Those teachers who are not competent in such programming areas are hesitant to fully embark on the use of GIS to facilitate teaching and enhance learning. From informal discussions with mainly geography teachers, a pessimistic view of GIS in the classroom emerged, principally because of time constraints. However, if this constraint were removed there was agreement that its potential educational impact is immense.

It is broadly agreed, therefore, from a Hong Kong perspective, that geomatics education, including the use of GIS as a tool, is a developing trend responding to the availability of more advanced technology to handle spatial science. This, as in many North American and European countries, should start at the preuniversity stage but it will be no easy task to accomplish it. We need a carefully designed curriculum progressing from high school to university levels; we need the corresponding support of appropriate expertise, time, hardware and software; we need a well-structured and user-friendly spatial database readily comprehended by both teachers and students; and above all we need the combined efforts of both government and the private sector as well as education policy makers and teachers.

\section{References}

Centre of Urban Planning and Environmental Management (2000) At http: / /www.hku. hk/cupem/. University of Hong Kong.

Department of Geography (2000) At http: / / www.geo.cuhk.edu.hk/ . Chinese University of Hong Kong.

Department of Geography (2000) At http://www.geog.hku.hk/. University of Hong Kong.

Department of Geography (2000) At http:/ / www.hkbu.edu.hk/index.html. Hong Kong Baptist University.

Department of Land Surveying and Geo-Informatics (2000) At http:/ /www. lsgi.polyu. edu.hk/. Hong Kong Polytechnic University.

Goodchild, M.F. and Kemp, K.K. (1990) Introduction to GIS, NCGIA Core Curriculum. National Center for Geographic Information Analysis, University of California, Santa Barbara, California.

LIC (2000) At http://www.info.gov.hk/landsd/mapping/web/page/smoindex.htm. Land Information Centre, Survey and Mapping Office, Lands Department, Hong Kong SAR Government. 